\title{
4-D Modeling of a Sustainable Economy: Integrating Economic, Environmental, Population, and Monetary Models
}

\author{
Frederick Betz \\ Institute for Policy Models and Portland State University, Portland, OR, USA \\ Email: fbetz@venture2reality.com
}

How to cite this paper: Betz, F. (2019) 4-D Modeling of a Sustainable Economy: Integrating Economic, Environmental, Population, and Monetary Models. Theoretical Economics Letters, 9, 1873-1885. https://doi.org/10.4236/tel.2019.96119

Received: January 29, 2019

Accepted: August 12, 2019

Published: August 15, 2019

Copyright (อ 2019 by author(s) and Scientific Research Publishing Inc. This work is licensed under the Creative Commons Attribution International License (CC BY 4.0).

http://creativecommons.org/licenses/by/4.0/

\section{(c) (i) Open Access}

\begin{abstract}
Leontief's Input-Output Analysis equation has long been used around the world and especially in China to calculate production and consumption balances. This research shows how to connect environmental and financial balances to production balances in an economic region by generalizing the Leontief's equations from vector form to tensor form. This is important for creating economic and environmental policies aimed at sustainable economies. It provides a general modeling approach which can quantitatively connect economic processes with biological and physical processes of the environment. If economic processes cannot be measured as to their real physical/biological impacts, one does not know whether or not such economic processes are sustainable in nature. The tensor generalization also enables the depiction of both economic processes as production and finance. The use of tensor mathematics for input-output models of both economy and its environment provides a data architecture to create simulation models of the environmental impact of an economy.
\end{abstract}

\section{Keywords}

Quantitative Economics, Sustainable Economy, Environmental Economics, Economic Models, Financial Models

\section{Introduction}

Leontief had formulated an economic model of national economy as an input-output balance of products produced and consumed. [1] He described the production $(P)$ from an economic sector (such as manufacturing or agriculture) as consisting of the sum of the $I$-th products $P_{I}$ produced in the region 
$\left(P=\sum_{I} P_{I}\right)$. Leontief then traced that quantity of production $P_{I}$ in distribution in the economy for consumers $\left(C_{I}\right)$ or for other $J$-th industrial sectors $\left(X_{I J}\right)$ or exported to other $K$-th countries $\left(E_{I K}\right)$ or imported $\left(I_{I K}\right)$ from other $K$-th countries. Leontief wrote this input-output economic model for a region as a vector equation:

$$
P_{I}+\sum_{K} I_{I K}=C_{I}+\sum_{J} X_{I J}+\sum_{K} E_{I K}
$$

This is a "balance" equation for a production system (balancing product production against product consumption) in a national economy. This reads as the quantity of production $P_{I}$ of the $I$-th product in an economic region plus the quantity of imports of the $I$-th product $\sum_{K} I_{I K}$ is distributed to the regional consumers $C_{I}$ of the $I$-th products and to the sum of the regional industrial purchasers $\sum_{J} X_{I J}$ of the $I$-th product and to exports $\sum_{K} E_{I K}$ to all the $K$-th countries. The summation $\left(\sum_{J}\right)$ is taken over all other $J$-th economic sectors, and the summations $\left(\sum_{K}\right)$ over all the other $K$-th nations.

Leontief's paper [1] received major attention and his model has been implemented throughout the world. For example in China, Liu Qiyn and Xaia Ming summarized the use of economic input-output analysis: "Because of the active efforts of Qian Xuesen and Hua Luogeng, the Operational Office of Mathematic Research of Chinese Academy of Sciences set up an economic research team in 1959 and began to investigate input-output technology... After the Cultural Revolution was launched, research work was interrupted and the application of input-output methods in China was stopped at that time... In 1973, under the approval of the State Development Planning commission, scholars... compiled an input-output table of 61 major products of China... In 1980, after the implementation of reform and opening-up policy... scholars proposed to the State Council to compile a new national input-output table and apply it to China's planned economic work... Thus far (by 2016), the National Statistical Bureau has compiled five basic input-output tables of the Chinese economy in 1987, 1992, 1997, 2002, 2007... [2]."

The importance of adding information about population and environment, into the production model of Leontief's input-output analysis model has long been recognized. For example in China, Liu Qiyn and Xia Ming wrote: “The most important achievement in theoretical input-output research was scored by Chen Xikang. In 1989, he became the first to put forward the notion of input-occupancy-output technique at an international conference... According to Chen, input-occupancy-output techniques not only studies... products... but also approaches the relationship between the product output... and its fixed assets, labor force and natural resources [2]."

Leontief received the Noble Prize in economics for his work. The equation depicts the production system of a nation but does not include other economic aspects, such as population, environment, and financial system. The purpose of this research is to generalize the input-output balance equations to include these other economic aspects. 


\section{Generalizing the Leontief Vector Equation to a Tensor Form}

A tensor form of an input-output balance equation provides a systematic and clear way to relate production to environment, by way of individual tensor planes and the quantitative connections between planes. In an earlier paper, the author first introduced a generalized tensor model, but with three planes (dimensions) of production, environment, and population-using tensor notation [3]. In this research, we add a fourth financial dimension to the tensor equation.

Since Leontief's equation is a vector equation, it can be generalized to a tensor equation, as vectors have one index of notation (usually indicated by a subscript) and tensors have two indices of notation (usually indicated by a subscript and a superscript). Then the product vector $\left(P_{I}\right)$ with the $I$-th subscript becomes a product tensor $P_{I}^{N}$ with the $I$-th subscript and an $N$-th superscript. In tensor notation, Leontief's equation generalizes to:

$$
P_{I}^{N}+\sum_{K} I_{I K}^{N}=C_{I}^{N}+\sum_{J} X_{I J}^{N}+\sum_{K} E_{I K}^{N}
$$

One can add a temporal dimension to the equation, to indicate the time period of the processes:

$$
P_{I}^{N}(t)+\sum_{K} I_{I K}^{N}(t)=C_{I}^{N}(t)+\sum_{J} X_{I J}^{N}(t)+\sum_{K} E_{I K}^{N}(t)
$$

The reason for this generalization is that while the $I$-th subscript can denote an $I$-th product in a region, the $N$-th superscript can denote $N$ different planes of processes in a region. Here we use $N=1$ to denote Leontief's economic plane of the region and $N=2$ to denote the physical-biological environmental plane of the region:

$$
\begin{gathered}
P_{I}^{1}+\sum_{K} I_{I K}^{1}=C_{I}^{1}+\sum_{J} X_{I J}^{1}+\sum_{K} E_{I K}^{1} \text {-the economic plane } \\
P_{I}^{2}+\sum_{K} I_{I K}^{2}=C_{I}^{2}+\sum_{J} X_{I J}^{2}+\sum_{K} E_{I K}^{2} \text {-the environmental plane }
\end{gathered}
$$

These are shown as parallel planes over a region in Figure 1.

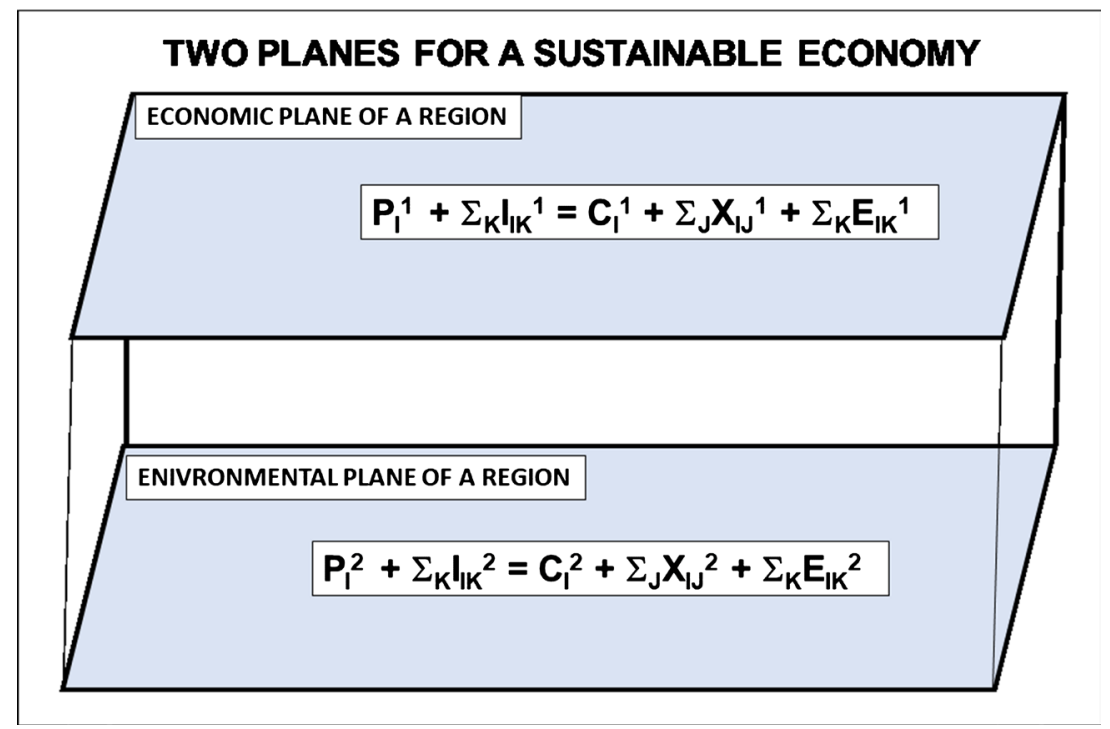

Figure 1. Tensor model with two planes: production and environment. 
The tensor equation is a set of vector equations of input-output balances of activities within a plane-an economic-plane-1 and an environmental-plane-2. In an economic-plane-1, the tensor Leontief equation is a balance equation between economic supply and demand in a given time period $(t)$. This means that in this period, the products $P_{I}^{1}$ produced or imported $\sum_{K} I_{I K}^{1}$ are all consumed or exported $C_{I}^{1}+\sum_{J} X_{I J}^{1}+\sum_{K} E_{I K}^{1}$ in the same period $(t)$ as supply is balanced against demand in that economy.

However, in an environmental-plane-2, some of the physical/biological things $P_{I}^{2}$ exist in the previous time period but are changed in quantity during the time period $(t)$. Thus the balance in the environmental-plane- 1 is about changes in the quantities of things from time $t_{0}$ to time $t_{1}$, which we denote as $\Delta P_{I}^{2}=P_{I}^{2}\left(t_{1}\right)-P_{I}^{2}\left(t_{0}\right)$. During this interval, the quantities of physical/biological things change as they are added (or consumed) $\pm C_{I}^{2}$ or used by other physical/biological processes $\sum_{J} X_{I J}^{2}$ or exported $\sum_{K} E_{I K}^{2}$ from the region. Then in the environmental-plane-2, the input-output balance equation becomes the changes $\Delta P_{I}^{2}$ of the things in the environment due to economic activity in plane-1 of the same period $(t)$; so one can write:

$$
\Delta P_{I}^{2}=\sum_{K} I_{I K}^{2} \pm C_{I}^{2}-\sum_{J} X_{I J}^{2}-\sum_{K} E_{I K}^{2}
$$

This means in an economic time period $(t)$, the changes in the quantity $\Delta P_{I}^{2}$ of physical/biological things in the environmental-plane- 2 due to economic activities in that region which can occur as:

Increased by things imported physically into that region from other $K$ regions: $+\sum_{K} I_{I K}^{2}$;

Increased (decreased) by things grown (taken) physically from (in) the region: $\pm C_{I}^{2}$;

Decreased by things used physically by other environmental processes of the region: $-\sum_{J} X_{I J}^{2}$;

Decreased by things exported physically from that region into other $K$ regions: $-\sum_{K} E_{I K}^{2}$.

In the environmental-plane-2, $P_{I}^{2}$ denotes not an economic product but an $I$-th physical or biological thing; and the quantity $\left(\sum_{K} I_{I K}^{2}\right)$ is the same physical or biological thing imported into the region. A physical thing may be a material (such as water or toposil) or an energy (such as wind or waves), and a biological thing may be a species (such as kinds of plants or animals). The quantity $\pm C_{I}^{2}$ is the amount of this thing grown (consumed) in the environment-plane-2. For example, topsoil may be added (eroded) or a species grown (exterminated). The quantity $X_{I J}^{2}$ is the amount of a thing involved in other processes in the environment $N=2$. For example, rain feeds watersheds and also rivers in the physical environment. Or for example in biological processes, herbivores feed carnivores. The quantity $E_{I K}^{2}$ expresses the amount of an $I$-th physical/biological thing exported from the regional environment into another region. For example, tributaries feed water from one region into a river in another region.

But also in this multiple plane notation $(N)$ one may wish to express the ex- 
changes of physical/biological things between the economic activities in plane-1 and the environmental processes in plane-2. Things from the environmental-plane-2 $(N=2)$ into the economic-plane $1(N=1)$ are often natural resources used in the production and consumption activities of the economy of a region. We will denote this as the resource tensor: $R_{G I}^{M N}$.

We define this quantity of resources $R_{G I}^{M N}$, where a $G$-th material/energy/biological resource from the environmental-plane-2 $(N=2)$ is used in the economic-plane-1 $(M=1)$ in the economic production of a unit of an I-th product (We will use the superscript notation of "to-from" as $\left.R_{G I}^{M(\text { to }) N(\text { from })}\right)$. To calculate this quantity of $G$-th resource taken from the environmental plane, one can use the idea of a production function $R_{G I}^{\prime 1}$, which is the quantity of $G$-th resource used to produce one unit of the $I$-th product. Then the quantity of the $G$-th resources used in producing $P_{I}^{1}$ quantities of the $I$-th product is: $R_{G I}^{12}=P_{I}^{1} R_{G I}^{\prime 1}$. This quantity of resources is taken from the environmental plane-2, so that the quantity of the $G$-th material/energy is diminished from the environment. Thus the quantity of physical/biological things consumed $C_{I}^{2}$ in the environmental-plane-2 due to economic activities of economic-plane- 1 is due to resource extraction activities. Thus we can set $C_{I}^{2}=R_{G I}^{12}$ and the environmental balance equation becomes:

$$
\Delta P_{I}^{2}=\sum_{K} I_{I K}^{2}-R_{G I}^{12}-\sum_{J} X_{I J}^{2}-\sum_{K} E_{I K}^{2}
$$

Also in the regional production and use of the I-th product in the economic-plane-1, there will be two kinds of waste created in that plane and sent into the environmental plane, a production waste and a consumption waste. The production waste $W_{H I}^{21}$ is the quantity of $H$-th waste created in the economic production of the I-th products; and can be calculated from per-unit waste quantities as $W_{H I}^{21}=P_{I}^{1} W_{H I}^{\prime 21}$, where $W_{H I}^{\prime 21}$ is the industrial waste production function per unit quantity of the $I$-th product. The consumption waste $H_{L I}^{21}$, which is the quantity of $L$-th waste created in the regional consumption of the $I$-th products, and can be calculated from per-unit consumption quantities as $H_{L I}^{21}=C_{I}^{1} H_{L I}^{\prime 21}$.

The industrial waste $W_{H I}^{21}$ and the consumption waste $H_{L I}^{21}$ are both disposed into the environmental-plane-2, so the environmental input-output balance equation due to economic activities becomes:

$$
\Delta P_{I}^{2}=\sum_{K} I_{I K}^{2}+W_{H I}^{21}+H_{L I}^{21}-R_{G I}^{12}-\sum_{J} X_{I J}^{2}-\sum_{K} E_{I K}^{2}
$$

Thus the generalized balance equation in the environmental-plane-2 interpreted as a balance of the changes to the quantities of physical/biological things, as shown in Figure 2.

Looking at the resource quantity from a plane- $N$ to a plane- $M$, the resources $R_{G I}^{12}$. In the economic plane are the $G$-th materials and/or energy supplies taken from the environmental-plane- 2 used in the production of the $J$-th products in the economic plane-1. The quantity of production waste $W_{H I}^{21}$, is the quantity of $H$-th waste created in the production of the $I$-th products in economic-plane- 1 sent to the environmental-plane-2. The consumption waste is $H_{L I}^{21}$. 
TWO PLANES FOR A SUSTAINABLE ECONOMY

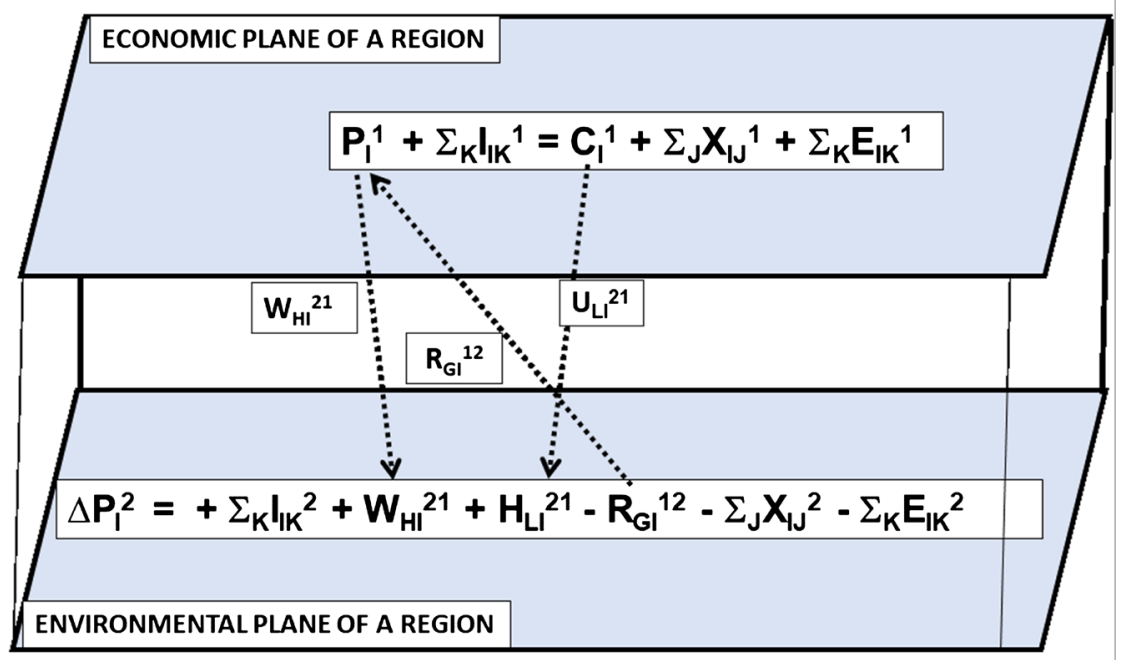

Figure 2. Tensor equation for a sustainable economy, linking economic production and environment.

This two-plane tensor input-out equation provides an integrated economicenvironmental model for:

1) A data architecture for descriptions of a geographical region as both economic production and environmental structures;

2) A basis for models analyzing the flows of materials/energy between economic production and physical/biological environments.

\section{Third Tensor Plane as a Population Plane}

Next is added a third balance equation for a demographic plane depicting the population living in a region. We consider the total pollution of a region in a time period to be compiled in the following equation:

Total Population $=$ Employed + Unemployed + Retired + Students

$$
\begin{aligned}
& + \text { Immigrants }- \text { Emigrants }+ \text { Births }- \text { Deaths }+ \text { Tourists } \\
& \qquad P^{3}(t)=\sum_{I=1}^{7} P_{I}^{3}-\sum_{I=8}^{9} P_{I}^{3}
\end{aligned}
$$

where:

$$
\begin{aligned}
& P_{1}^{3}=\text { Employed Population; } \\
& P_{2}^{3}=\text { Unemployed Population; } \\
& P_{3}^{3}=\text { Retired Population; } \\
& P_{4}^{3}=\text { Student Population; } \\
& P_{5}^{3}=\text { Annual Births; } \\
& P_{6}^{3}=\text { Annual Immigrants; } \\
& P_{7}^{3}=\text { Annual Tourists; } \\
& P_{8}^{3}=\text { Annual Deaths; } \\
& P_{9}^{3}=\text { Annual Emigrants. }
\end{aligned}
$$

Looking at the resource quantity from a Population plane-3 to Environment plane-2, the resources $R_{G I}^{23}$ in the economic plane are the $G$-th materials and 
water taken from the environmental-plane- 2 used in consumption by the population in plane 3 (Figure 3 ). The quantity of population waste $H_{L I}^{32}$ goes from the population to the environment.

\section{Fourth Tensor Plane as a Financial Plane}

In this research, we now add a fourth plane to summarize the financial transactions in the economy of the region:

$$
\begin{gathered}
P_{I}^{1}+\sum_{K} I_{I K}^{1}=C_{I}^{1}+\sum_{J} X_{I J}^{1}+\sum_{K} E_{I K}^{1} \text { - the economic plane } \\
\Delta P_{I}^{2}=\sum_{K} I_{I K}^{2}+W_{H I}^{21}+H_{L I}^{21}-R_{G I}^{12}-\sum_{J} X_{I J}^{2}-\sum_{K} E_{I K}^{2} \text { - the environmental plane } \\
P^{3}(t)=\sum_{I=1}^{7} P_{I}^{3}-\sum_{I=8}^{9} P_{I}^{3} \text { - the population plane } \\
P_{I}^{4}+\sum_{K} I_{I K}^{4}=C_{I}^{4}+\sum_{J} X_{I J}^{4}+\sum_{K} E_{I K}^{4} \text { - the financial plane }
\end{gathered}
$$

The balance equation for the fourth plane, the financial plane, needs to be appropriate to the transactions occurring in the financial system. One form of a balance equation appropriate to financial transactions can be an adaptation of the traditional financial accounting equation: Equity = Assets - Liabilities. In monetary theory, two kinds of financial sectors need to be distinguished in a national economy, as a public sector and a private sector. The national accounting equation should show variables for both public and private sectors.

For example, L. Randall Wray wrote: "It is often useful to distinguish among different types of sectors in the economy. The most basic distinction is between the public sector (including all levels of government) and the private sector (including

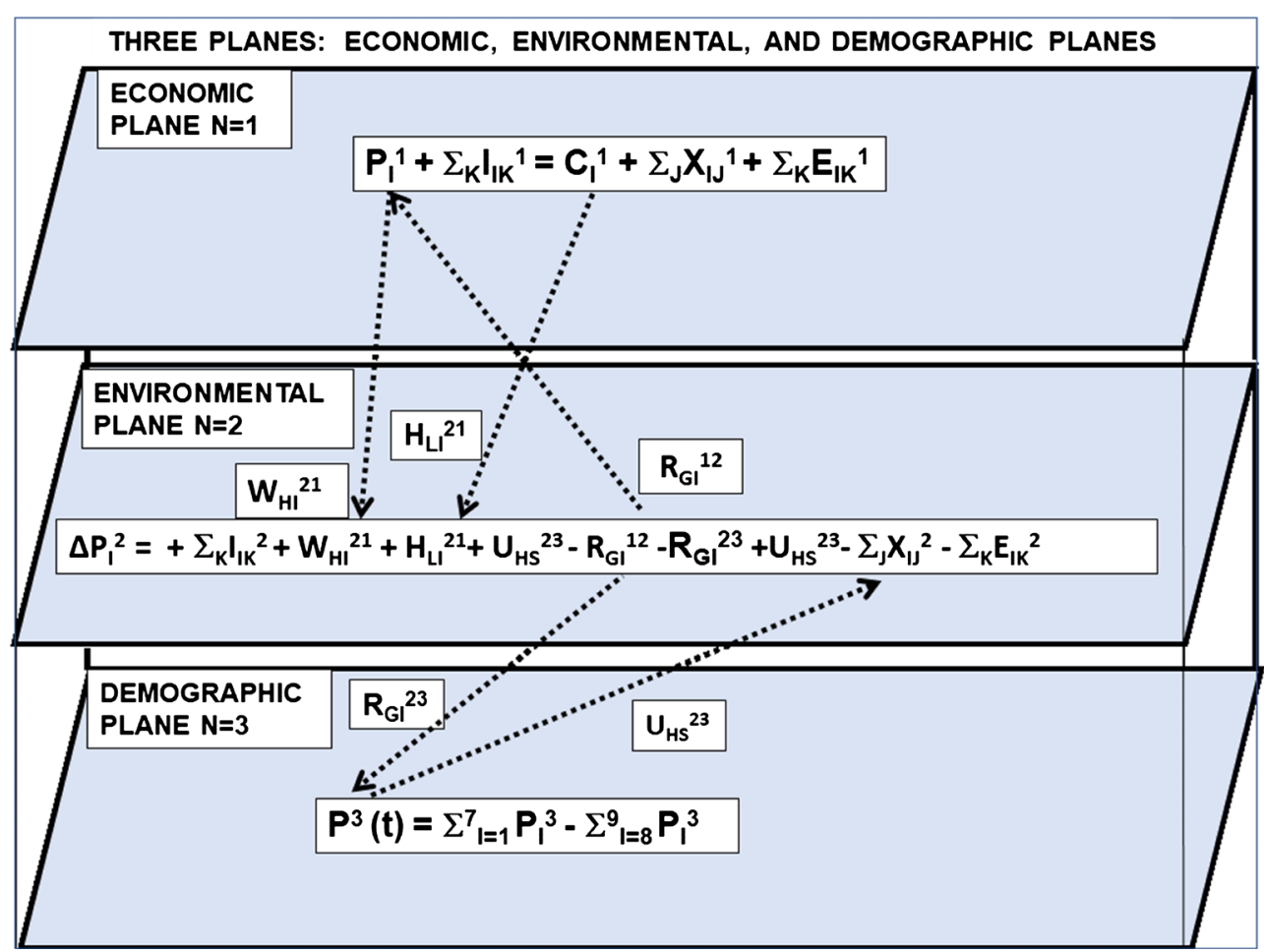

Figure 3. Three planes: economic, environmental and demographic. 
households and firms)" [4]. Wray also proposed to use an "accounting balance-sheet" approach between public and private sectors of a national economy. [4]. The author used this monetarist approach in depicting currency flow in the Indian economy [5]. Now we use this approach to specify the balance equation for the Finance tensor plane:

(Private Equity $M_{I}^{4}$ and Public Equity $N_{I}^{4}$ ) $=\left(\right.$ Private Assets $A_{I}^{4}$ and Public Assets $\left.B_{I}^{4}\right)$ -(Private Liabilities $L_{I}^{4}$ and Public Liabilities $\left.K_{I}^{4}\right)$

$$
\left(\sum_{I} M_{I}^{4}+\sum_{I} N_{I}^{4}\right)=\left(\sum_{I} A_{I}^{4}+\sum_{I} B_{I}^{4}\right)-\left(\sum_{I} L_{I}^{4}+\sum_{I} K_{I}^{4}\right)
$$

$M_{I}^{4}=$ Equity-Private Sector

$M_{1}^{4}=$ Domestic Stock Market;

$M_{2}^{4}=$ Foreign Stocks Owned Domestically;

$M_{3}^{4}=$ Domestic Sovereign Bond Market;

$M_{4}^{4}=$ Foreign Sovereign Bond Owned Domestically;

$M_{5}^{4}=$ Corporate Bond Market;

$M_{6}^{4}=$ Property Market;

$M_{7}^{4}=$ Hedge Fund Market.

$A_{I}^{4}=$ Assets-Private Sector;

$A_{1}^{4}=$ Executive Salaries and Bonuses;

$A_{2}^{4}=$ Labor Salaries;

$A_{3}^{4}=$ SME Business Owner Salaries;

$A_{4}^{4}=$ Corporate Dividends;

$A_{5}^{4}=$ Bond Interest;

$A_{6}^{4}=$ Property Rent;

$A_{7}^{4}=$ Loan Interest;

$A_{8}^{4}=$ Government Contracts.

$L_{I}^{4}=$ Liabilities-Private Sector.

$L_{1}^{4}=$ Corporate Debt;

$L_{2}^{4}=$ Corporate Bonds;

$L_{3}^{4}=$ Private Bank Loans;

$L_{4}^{4}=$ Credit Card Debt;

$L_{5}^{4}=$ Property Mortgages.

$N_{I}^{4}=$ Equity-Public Sector.

$N_{1}^{4}=$ Public' Corporations;

$N_{2}^{4}=$ Central Bank Reserves;

$N_{3}^{4}=$ State-Owned Corporations.

$B_{I}^{4}=$ Assets-Public Sector.

$B_{1}^{4}=$ Income Tax Revenue;

$B_{2}^{4}=$ Value-Added Tax Revenue;

$B_{3}^{4}=$ Property Tax Revenue;

$B_{4}^{4}=$ Tariff Tax Revenue;

$B_{5}^{4}=$ State-Owned Corporations Revenue. 
$K_{I}^{4}=$ Liabilities-Public Sector.

$K_{1}^{4}=$ New Issue of Sovereign Bonds;

$K_{2}^{4}=$ Interest and Payoff of Issued Sovereign Bonds;

$K_{3}^{4}=$ Government Current Budget Deficit;

$K_{4}^{4}=$ State-Owned Corporate Debt.

We know that in financial systems, a time dimension is essential to characterize the system. Time dimensions periodically appear in financial systems (1) as business cycles in an economy and (2) as Minsky financial bubbles in financial markets and (3) as fiscal crises such as inflation or government-debt default. We can introduce again temporal dependence in the 4-dimensional tensor equations:

$$
\left(M_{I}^{4}(t)+N_{I}^{4}(t)\right)=\left(A_{I}^{4}(t)+B_{I}^{4}(t)\right)-\left(L_{I}^{4}(t)+K_{I}^{4}(t)\right)
$$

However, since financial bubbles and business cycles only periodically occur, we can indicate their occurrence during a year as a sudden increment or decrement to markets or assets.

$$
\begin{aligned}
& \left(M_{I}^{4} \pm \Delta M_{I}^{4}\left(t_{1}\right)+N_{I}^{4} \pm \Delta N_{I}^{4}\left(t_{1}\right)\right) \\
& =\left(A_{I}^{4} \pm \Delta A_{I}^{4}(t)+B_{I}^{4} \pm \Delta B_{I}^{4}(t)\right)-\left(L_{I}^{4}(t) \pm \Delta L_{I}^{4}(t)+K_{I}^{4}(t) \pm \Delta K_{I}^{4}(t)\right)
\end{aligned}
$$

\section{Business Cycle}

Here we only depict the temporal impacts of the business cycle. In Figure 4, we indicate the impact of a business cycle beginning at time $t_{1}$ in an accounts period of time $t$.

Business cycles occur from the anticipation of producers as whether or not their markets grow. Since products take time to produce, producers must anticipate market growth or decline. When producers anticipate market growth $\left[+\Delta M_{I}^{4}\left(t_{1}\right)\right]$, then

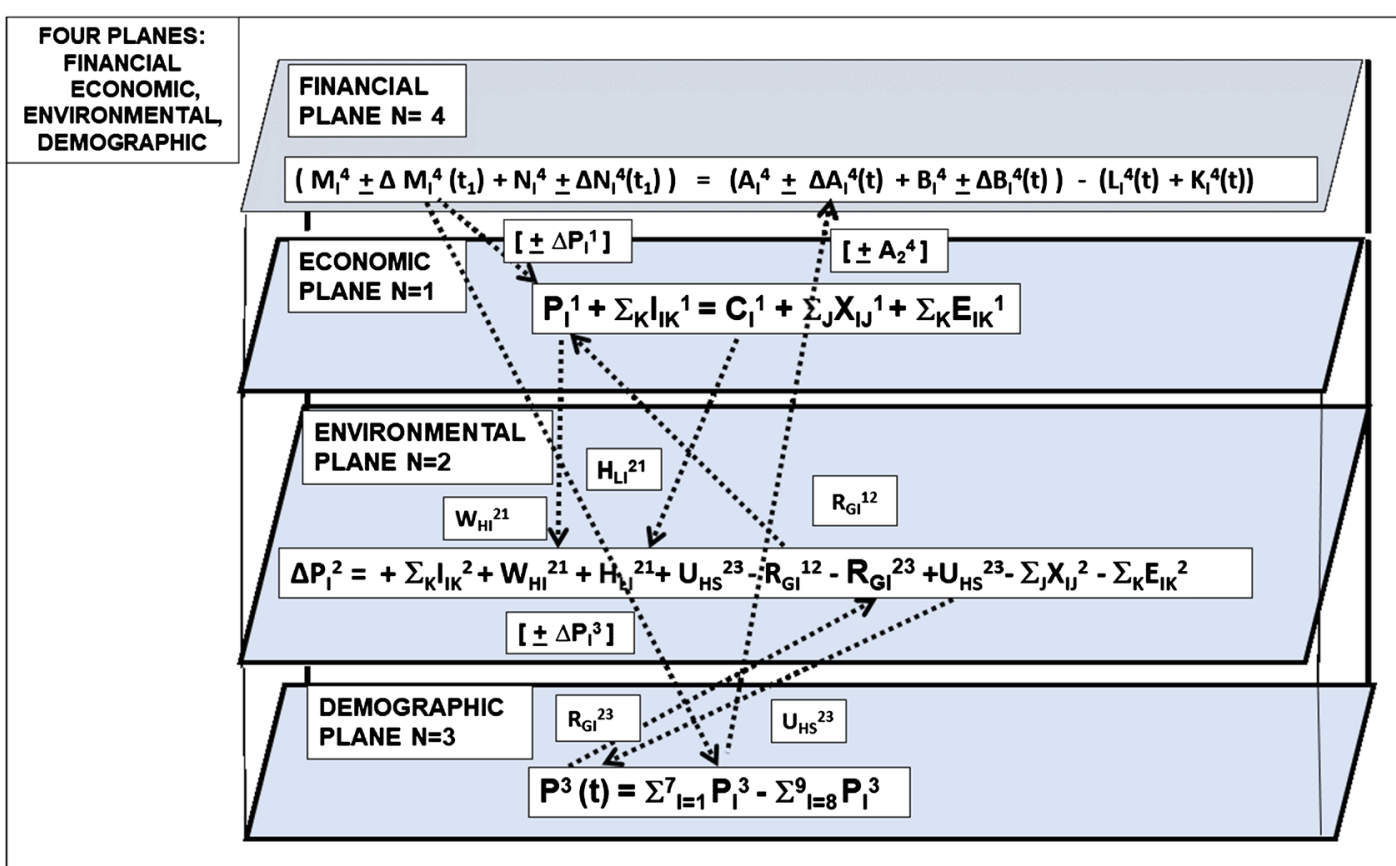

Figure 4. Four planes of a region: financial, economic, environmental, demographic. 
they increase production $\left[+\Delta P_{I}^{1}\right]$. Also they hire employees to increase production, increasing the employed population $\left[+\Delta P_{I}^{3}\right]$. But when producers anticipate market shrinkage $\left[-\Delta M_{I}^{4}\left(t_{1}\right)\right]$, then they decrease production $\left[-\Delta P_{I}^{1}\right]$. Also, they lay off employees to decrease costs, thereby decreasing the employed population $\left[-\Delta P_{I}^{3}\right]$ and increasing unemployment. And as employment increases or decreases, private assets of labor salaries $\left[ \pm A_{2}^{4}\right]$ increase or decrease. This is shown in Figure 4.

This four-plane model of a tensor Leontief type balance equation shows how to integrate in a region, the economic processes of production and finance with environmental processes and population demographics.

\section{Case Study: Gas Replacing Coal in Hebei Province, China}

This case is an example of a government policy to improve the environment by substituting gas for coal, decreasing atmospheric pollution. Lucy Hornby and Archie Zhang wrote: “The warm steam inside the village hair-dresser's shop feels unusually clean on a cold winter day: in Juncheng, in Heibei province, piped gas has taken the place of coal that used to leave a sticky residue over every surface. The cleanliness comes at a cost, calculated down to the penny by the half-dozen customers waiting their turn for a wash and a haircut. Gas is more expensive than coal, but for the moment, the government is paying [6]."

To model this kind of interaction between the economy, the environment, and people, a tensor Leontief model could map the quantities of the interactions between the production plane, the financial plane, the environment plane, and the population plane-in the region of Hebei Province.

There were financial costs to the government in encouraging the Hebei population to change from coal fuel to gas fuel. Lucy Hornby and Archie Zhang wrote: "The government has promised homeowners a Rmb1 subsidy for every cubic meter of natural gas bought over the first three years, to overcome the Rmb 2000 difference between heating a home with coal for the winter and heating it with gas [6]."

The small amount of the subsidy times the large population of the province resulted in significant expenditure by the provincial government. Lucy Hornby and Archie Zhang wrote: "In recent years, a wave of subsidy spending has propped up the economy in hundreds of small towns and villages that surround Beijing. From ecological toilets to cash payments for heating homes with gas, the payouts have helped soften the economic cost of a campaign to improve air quality in the smoggy capital... Hebei is a test case for China's ability to find alternative economic models as it weans itself off heavily polluting industry [6]."

In this case, the application of type of Leontief tensor model would help the government estimate the cost of remediation and the scale of improvement in the environment. Government policies which improve the environment and stabilize social conditions are in the public welfare responsibilities of a government. Lucy Hornby and Archie Zhang wrote: "Zhu Ning, Associate Dean of the National Institute of Financial Research at Tsinghua University said: "It makes 
sense to improve social welfare and ensure social stability [6].”

A Leontief tensor model of a province as large as Hebei would be significant both in utility and size. Lucy Hornby and Archie Zhang wrote: "Hebei Province has an economy of the size of Poland's and twice as many people. Its mills produce a quarter of China's steel. The province allocates about 6 percent of its budget to reduce emission by heavy industry... [6]"

This case shows the practical importance of tensor Leontief models to assist the formulation and implementation of public policies for sustainable economies, also serving the public welfare.

\section{Integration of Economic Modeling}

Integrating economic modeling and environmental modeling is essential to understanding the impact of industrialization. The long-term consequence of industrialization requires that one should model not only the production in an economic region but also the environment in the region and also measure the interconnection between the two. The first reason for this is that industrial production requires materials $\mathrm{R}_{\mathrm{GI}}^{12}$ extracted from the environment and used as resources for production in the economy. In fact, global industrialization is now threatened by too much fossil fuel (coal, oil, gas) resources being extracted from the global environment and burned-resulting in altering the environment through global warming. The second reason is that industrialization generates waste in both the production $\mathrm{W}_{\mathrm{HI}}^{21}$ and consumption $\mathrm{H}_{\mathrm{LI}}^{21}$ of products/services; and the waste is dumped into the environment. In fact, over-fishing of the oceans, pollution and global warming in the oceans are seriously harming the fishing industry and even resulting in some ocean species extinction.

Integrating production modeling and financial modeling is also essential to understanding an economy, since production and finance are two basic systems in a modern economy. Historically, this approach was pioneered by John Maynard Keynes when he reformulated traditional economic models. Hendrik Van den Berg wrote: "When Keynes published his General Theory in 1936, the neoclassical paradigm was well-established in the economics profession... (and afterwards) the growth models were derived from Keynesian macroeconomic foundations by Roy Harrod and Evsey Domar. They independently developed what turned out to be identical growth models, which we now refer to as the Harrod-Domar model... Harrod and Domar pointed out that investment changed the economy's supply side as well as the demand side, and full employment could be maintained only if investment and the other sources of aggregate demand grew just fast enough to exactly absorb the increased output that the new investment made possible [7]." The later Solow model is also one of supply depending upon investment; and Solow added labor [8].

As described by Hendrik Van den Berg, the Harrod-Domar model consisted of two parts, a supply-side model of production and a demand-side model of demand. The demand side was controlled by balancing production to consump- 
tion; and the supply side was controlled by investment to expand production. As shown in Figure 5, the author published systems dynamics versions of a Harrod-Domar model for the supply side and a Leontief model for the demand side [9] [10].

This kind of a quantitative model is a dynamic model, whereas the traditional Leontief model is a static model, a summary of the production dynamics over a time period. In the Leontief demand side, the dynamics is the flow of product-demands influencing product production at any time $t$ in the production process. In the Harrod-Domar supply side, the dynamical flows are investments into production or other capital uses at a time $t$. Dynamical models trace flows over time. Static models summarize the results of flows after a period of time $\Delta t=\left(t_{2}-t_{1}\right)$.

The traditional Harrod-Domar macro-economic model depicted the supply side as being fostered by capital investments in production capacity, assuming all investment went into production supply. However, a modern systems-version of Harrod-Domar depicts the different uses of investment, only one of which is to increase production supply [10].

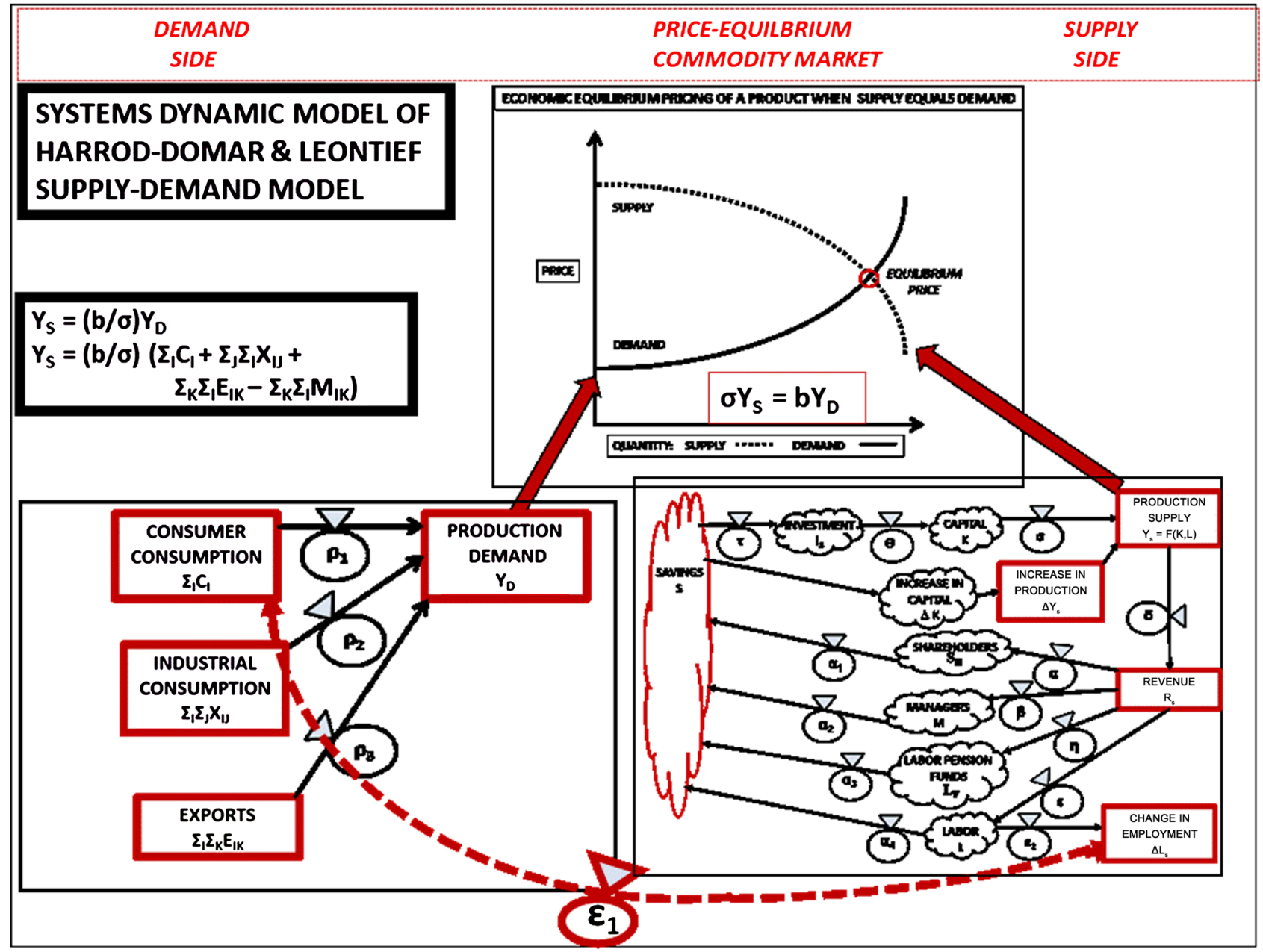

Figure 5. Integrated macro-economic model with leontief as demand-side and harrod-domar as supply side. 
In summary, the four-plane tensor model of Leontief-type balance equations provides a static summary of a time period, which integrates the dynamics of the economic processes of production and finance with environmental processes and population dynamics.

\section{Conflicts of Interest}

The author declares no conflicts of interest regarding the publication of this paper.

\section{References}

[1] Leontief, W.W. (1986) Input-Output Economics. 2nd Edition, Oxford University Press, New York. https://doi.org/10.1057/978-1-349-95121-5_1072-1

[2] Liu, Q. and Xia, M. (2016) Application and Development of Input-Output Analysis in China. In: Zhang, A., Wang, T. and Ge, X., Eds., Quantitative Economics in China, World Scientific Publishing Co., Singapore, 79-95. https://doi.org/10.1142/9789814675680_0006

[3] Betz, F. (2013) Modeling Sustainable Economy: Integrating Economic, Environmental, and Population Models. International Journal of Innovation and Technology Management, 10, Article ID: 1350007. http://www.icpress.co.uk https://doi.org/10.1142/S0219877013500077

[4] Wray, R. (2015) Modern Money Theory. 2nd Edition, Palgrave Macmillan, London. https://doi.org/10.1057/9781137539922

[5] Betz, F., Anderson, T.R. and Kalathil Puthanpura, A. (2018) Currency Flow in an Economy: India's Demonetarization Event. Theoretical Economics Letters, 8, 476-484. http://www.scirp.org/journal/tel https://doi.org/10.4236/tel.2018.83033

[6] Lucy, H. and Zhang, A. (2019) Subsidies Replace Factories as China Fights Pollution. Financial Times. 3.

[7] Van den Berg, H. (2013) Growth Theory after Keynes, Part I: The Unfortunate Suppression of the Harrod-Domar Model. The Journal of Philosophical Economics, 7, 2-28.

[8] Solow, R.M. (1956) A Contribution to the Theory of Economic Growth. The Quarterly Journal of Economics, 70, 65-94. http://www.jstor.org/stable/1884513 https://doi.org/10.2307/1884513

[9] Betz, F. (2015) Disequilibrium Systems Representation of Growth Models-Harrod-Domar, Solow, Leontief, Minsky, and Why the U.S. Fed Opened the Discount Window to Money-Market Funds. Modern Economy, 6, 1189-1208. http://www.scirp.org/journal/me https://doi.org/10.4236/me.2015.612113

[10] Betz, F. (2018) Capital Structures: Vectorizing the Harrod-Domar Model in Macro-Economics. Theoretical Economics Letters, 8, 2682-2706.

https://doi.org/10.4236/tel.2018.812170

http://www.scrip.org/journal/tel 